\title{
Profile of childhood blindness and low vision in Yemen: a hospital-based study
}

M.A. Bamashmus ${ }^{1,2}$ and S.A. Al-Akily

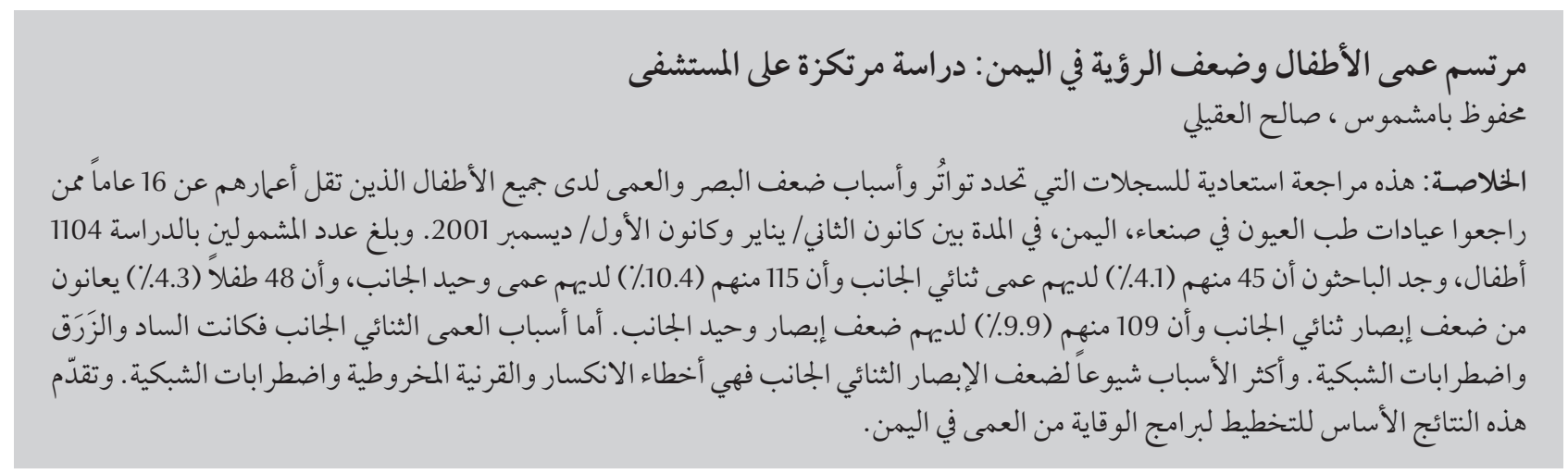

ABSTRACT A retrospective review of records determined the frequency and causes of low vision and blindness in all children aged $<16$ years attending an ophthalmic practice in Sana'a, Yemen between January and December 2001. Of the 1104 children studied, 45 (4.1\%) were found to have bilateral blindness and 115 (10.4\%) were unilaterally blind; 48 children (4.3\%) were bilaterally visually impaired and 109 (9.9\%) were unilaterally visually impaired. The main causes of bilateral blindness included cataract, glaucoma and retinal disorders. The most common causes of bilateral low vision included refractive errors, keratoconus and retinal disorders. These results provide a basis for planning blindness prevention programmes in Yemen.

\section{Profil de la cécité et de la basse vision chez l'enfant au Yémen : une étude hospitalière}

RÉSUMÉ Une étude rétrospective de dossiers médicaux a permis de définir la fréquence et les causes de la basse vision et de la cécité chez tous les enfants de moins de 16 ans ayant consulté dans un cabinet ophtalmologique à Sanaa, au Yémen, entre janvier et décembre 2001. Sur 1104 enfants, 45 d'entre eux (soit 4,1\%) souffraient d'une cécité bilatérale, et 115 (10,4\%), d'une cécité unilatérale ; 48 enfants (4,3\%) présentaient une déficience visuelle bilatérale et 109 (9,9\%), une déficience visuelle unilatérale. Les principales causes de la cécité bilatérale comprenaient la cataracte, le glaucome et les affections rétiniennes. Les causes les plus fréquentes de la déficience visuelle bilatérale étaient quant à elles, les vices de réfraction, le kératocône et les affections rétiniennes. Ces résultats offrent une base pour la planification des programmes de prévention de la cécité au Yémen. 


\section{Introduction}

Blindness constitutes a significant public health problem in many countries. Despite the efforts of United Nations agencies, national governments and nongovernmental organizations, increasing life expectancy means that the numbers of people with visual impairment are increasing. Visual impairment is both detrimental to the quality of life for the individual and an economic burden on the individual, family and society in general $[1]$.

Blindness in childhood may interfere with the normal development and education of a child. There are about 1.5 million blind children, and this number appears to be increasing. Approximately 500000 children become blind every year (i.e. 1 every minute) and about half of them die within 1 or 2 years of becoming blind. Approximately onethird of the total economic cost of blindness is thought to be due to childhood blindness [2]. In developing countries, the causes of childhood blindness have not been widely studied. To plan effective intervention and prevention programmes, an awareness of the causes of blindness and the magnitude of the problem is crucial.

In Yemen, the family health survey conducted by the Ministry of Health in 2003 revealed that $2.9 \%$ of the population had some sort of self-reported handicap, with visual handicap representing $36 \%$ of the total identified disabled individuals in the country [3]. The country is poor, with a human development index of 0.486 , human poverty index of 47.0, life expectancy of 61.1 years and average literacy rate of only $50 \%$ $[4,5]$. Some studies on the prevalence and causes of blindness in Yemen have been done in focal areas of the country $[6,7]$, but to our knowledge there have been no published hospital-based studies on the causes of childhood blindness and low vision in Yemen. The present study aimed to determine the frequency and causes of low vision and blindness in children attending an ophthalmic practice in Sana'a, the capital of Yemen.

\section{Methods}

We studied 1104 consecutive records of children (588 males and 516 females) who attended the Ibn Al-Haitham eye centre in Sana'a during the period January 2001 to December 2001. The study was restricted to children aged 16 years and below. The records of medical history, family history and ophthalmologic evaluation were reviewed. The frequency of low vision and blindness were analysed by age and sex and the causes of blindness were noted.

Visual acuity at this eye centre is measured using the Snellen chart; for those aged 0-2 years Cardiff cards are used and for those aged $2-4$ years naming pictures or matching tests are used. Eye examination includes slit-lamp, fundoscopy, retinoscopy and tonometry when needed. After establishing the diagnosis, medicines or glasses are prescribed as appropriate.

Binocular blindness was defined as a corrected visual acuity of $3 / 60$ or below in both eyes [3]. Low vision was defined as visual acuity less than $6 / 18$ but better than $3 / 60$ with best possible correction. Uniocular blindness was defined as a corrected visual acuity $3 / 60$ or below in one eye [8].

In most cases the cause of blindness was a single disorder. When there was more than 1 disorder mentioned in the patient's record, the World Health Organization recommendation was adhered to, i.e. the most avoidable or preventable cause was chosen or, alternatively, the cause that led to the last event rendering the individual sightless [2]. This principle was also adhered to while classifying the causes of blindness in unilateral cases when multiple causes were recorded in 1 eye.
Data were entered into a Microsoft Excel 2000 programme.

\section{Results}

Out of this sample of 1104 children attending an ophthalmologic clinic, a total of 45 (4.1\%) had bilateral blindness, 115 (10.4\%) were unilaterally blind, 48 (4.3\%) were bilaterally visually impaired and 109 (9.9\%) were unilaterally visually impaired.

Table 1 shows the age and sex distribution of children with blindness and low vision. The proportion of boys who suffered from bilateral or unilateral blindness was $55.6 \%$ and $54.8 \%$ respectively, compared with $53.6 \%$ in the whole sample. The proportion of those aged $0-4$ years with bilateral blindness (48.9\%) was much higher than in the whole sample (18.8\%).

The commonest causes of bilateral blindness were cataract (20.0\%), glaucoma (17.8\%), retinal disorders (13.3\%) and corneal nontraumatic opacities (13.3\%) (Table 2). For unilateral blindness the main cause was cataract (34.8\%), followed by traumarelated complications (19.1\%), corneal nontraumatic opacity (10.5\%) and amblyopia (10.4\%).

Bilateral low vision was mainly due to refractive error (29.2\%), keratoconus (18.7\%), retinal disorder (18.7\%) and cataract (8.3\%) (Table 3). The main causes of unilateral low vision were amblyopia (25.7\%), trauma-related complications (23.9\%), refractive error $(17.4 \%)$, cataract $(11.9 \%)$ and corneal nontraumatic opacity (11.9\%).

\section{Discussion}

Many reports on childhood blindness in the Eastern Mediterranean region have been published over the last decade. Worldwide, the major causes of blindness in children include retinal 


\begin{tabular}{|c|c|c|c|c|c|c|c|c|c|c|}
\hline \multirow[t]{3}{*}{ Variable } & \multirow{2}{*}{\multicolumn{2}{|c|}{$\begin{array}{l}\text { Normal vision } \\
\quad(n=786)\end{array}$}} & \multicolumn{4}{|c|}{ Blindness } & \multicolumn{4}{|c|}{ Low vision } \\
\hline & & & \multicolumn{2}{|c|}{$\begin{array}{c}\text { Bilateral } \\
(n=45)\end{array}$} & \multicolumn{2}{|c|}{$\begin{array}{l}\text { Unilateral } \\
(n=115)\end{array}$} & \multicolumn{2}{|c|}{$\begin{array}{l}\text { Bilateral } \\
(n=48)\end{array}$} & \multicolumn{2}{|c|}{$\begin{array}{l}\text { Unilateral } \\
(n=109)\end{array}$} \\
\hline & No. & $\%$ & No. & $\%$ & No. & $\%$ & No. & $\%$ & No. & $\%$ \\
\hline \multicolumn{11}{|l|}{ Sex } \\
\hline Male & 421 & 53.6 & 25 & 55.6 & 63 & 54.8 & 22 & 45.8 & 57 & 52.3 \\
\hline Female & 366 & 46.6 & 20 & 44.4 & 52 & 45.2 & 26 & 54.2 & 52 & 47.7 \\
\hline \multicolumn{11}{|c|}{ Age (years) } \\
\hline $0-4$ & 148 & 18.8 & 22 & 48.9 & 27 & 23.5 & 5 & 10.4 & 18 & 16.5 \\
\hline $5-9$ & 205 & 26.1 & 9 & 20.0 & 34 & 29.6 & 11 & 22.9 & 34 & 31.2 \\
\hline $10-16$ & 434 & 55.2 & 14 & 31.1 & 64 & 55.7 & 32 & 66.7 & 57 & 52.3 \\
\hline
\end{tabular}

dystrophies, congenital cataract, congenital glaucoma, corneal opacities, trauma related complications, optic atrophy and vitamin A deficiency [9].

The prevalence of blindness and low vision in Yemen has not been studied in community-based surveys. An estimate of the prevalence of visual impairment around the world reported the prevalence of blindness in Yemen as $1.5 \%-2 \%$ [10]. A previous hospitalbased study showed that the most common causes of blindness among adult Yemenis included cataract, glaucoma, diabetic retinopathy, age-related macular degeneration and corneal opacity [11].

In our study of children attending an ophthalmology clinic in Sana'a, boys tended to outnumber girls. There are many possible reasons for this: boys may be at greater risk of blinding conditions than girls or blind girls may have a higher mortality rate than blind boys or the parents of blind boys may be more willing to seek eye care than the parents of blind girls.

Congenital eye problems (congenital cataract and congenital glaucoma) were a major cause of childhood blindness and low vision in Yemen, which may be related to the high rate of consanguineous marriages [3]. Another reason may be poor eye care services for children in this country. For example, the results of cataract surgery in children with congenital cataract are frequently poor because the treatment and postoperative care of these children requires special surgical experience and expensive equipment. The outcome would be improved if all congenital cataracts were operated on in tertiary eye centres [9]. There are also problems of awareness and delays in care-seeking by parents. Unfortunately, the parents of many children with congenital glaucoma delay seeking medical advice until the disease has reached the end stage [12].

Hereditary retinal dystrophies remained one of the main causes of bilateral blindness and low vision. Again this can be explained by the fact that consanguineous marriages are very common in Yemen [3], which may increase the incidence of the hereditary diseases.

\begin{tabular}{|c|c|c|c|c|c|c|}
\hline \multirow[t]{2}{*}{ Cause } & \multicolumn{2}{|c|}{$\begin{array}{l}\text { Bilateral blindness } \\
\quad(n=45)\end{array}$} & \multicolumn{2}{|c|}{$\begin{array}{l}\text { Unilateral blindness } \\
\qquad(n=115)\end{array}$} & \multicolumn{2}{|c|}{$\begin{array}{c}\text { Total } \\
(n=160)\end{array}$} \\
\hline & No. & $\%$ & No. & $\%$ & No. & $\%$ \\
\hline Cataract & 9 & 20.0 & 40 & 34.8 & 49 & 30.5 \\
\hline Glaucoma & 8 & 17.8 & 3 & 2.6 & 11 & 6.9 \\
\hline Retinal disorder & 6 & 13.3 & 0 & 0.0 & 6 & 3.8 \\
\hline Corneal opacity (microbial \& dystrophy) & 6 & 13.3 & 12 & 10.5 & 18 & 11.3 \\
\hline Optic nerve disease & 5 & 11.1 & 3 & 2.6 & 8 & 5.0 \\
\hline Refractive error & 3 & 6.7 & 2 & 1.7 & 5 & 3.1 \\
\hline Trauma complication & 2 & 4.4 & 22 & 19.1 & 24 & 15.0 \\
\hline Retinal detachment & 1 & 2.2 & 8 & 7.0 & 9 & 5.6 \\
\hline Keratoconus & 1 & 2.2 & 2 & 1.7 & 3 & 1.9 \\
\hline Amblyopia & 0 & 0.0 & 12 & 10.4 & 12 & 7.5 \\
\hline Retinal tumour & 0 & 0.0 & 7 & 6.1 & 7 & 4.4 \\
\hline Other & 4 & 9.0 & 4 & 3.5 & 8 & 5.0 \\
\hline
\end{tabular}




\begin{tabular}{|c|c|c|c|c|c|c|}
\hline \multirow[t]{2}{*}{ Cause } & \multicolumn{2}{|c|}{$\begin{array}{c}\text { Bilateral low } \\
\text { vision } \\
(n=48)\end{array}$} & \multicolumn{2}{|c|}{$\begin{array}{c}\text { Unilateral low } \\
\text { vision } \\
(n=109)\end{array}$} & \multicolumn{2}{|c|}{$\begin{array}{c}\text { Total } \\
(n=157)\end{array}$} \\
\hline & No. & $\%$ & No. & $\%$ & No. & $\%$ \\
\hline Refractive error & 14 & 29.2 & 19 & 17.4 & 33 & 21.0 \\
\hline Keratoconus & 9 & 18.7 & 3 & 2.8 & 12 & 7.6 \\
\hline Retinal disorder & 9 & 18.7 & 0 & 0.0 & 9 & 5.8 \\
\hline Cataract & 4 & 8.3 & 13 & 11.9 & 17 & 10.8 \\
\hline Amblyopia & 4 & 8.3 & 28 & 25.7 & 32 & 20.4 \\
\hline Glaucoma & 3 & 6.3 & 2 & 1.8 & 5 & 3.2 \\
\hline Trauma complication & 2 & 4.2 & 26 & 23.9 & 28 & 17.8 \\
\hline Ectopia lentis & 2 & 4.2 & 0 & 0.0 & 2 & 1.3 \\
\hline Corneal opacity & 1 & 2.1 & 13 & 11.9 & 14 & 8.9 \\
\hline Other & 0 & 0.0 & 5 & 4.6 & 5 & 3.2 \\
\hline
\end{tabular}

Trauma-related complications were also major causes of unilateral blindness and low vision in our study. According to a published article about childhood eye injuries in Yemen, road traffic accidents accounted for the highest number of serious injuries [13]. Fights and stonethrowing were also common causes of eyeinjuries, while sharp objects, gunshots and bomb explosions also accounted for childhood injuries [13].

Microbial infections or corneal dystrophies causing corneal opacity were important causes of unilateral and bilateral blindness. Many children become blind from corneal opacity every year [14].

Preventable causes of blindness (e.g. trauma-related complications) can be tackled by improving the primary levels of health care delivery, whereas treatable causes (e.g. cataract, glaucoma, amblyopia, refractive errors) require specialized, paediatric ophthalmology units, systems for early identifications and referral and increased public awareness.
A comprehensive approach is therefore needed for prevention and treatment of blindness and low vision, including providing low-vision aid services for children with low vision.

Prevention and reduction of childhood blindness in Yemen can be achieved by public education programmes. Consanguineous marriage should be discouraged and genetic counselling should be done when a hereditary disease is suspected. Early intervention for cataract cases in specialized centres and treating refractive errors and amblyopia would have a major impact on the reduction of childhood blindness. Prevention of trauma-related injuries could be improved through care in the use of hazardous toys, prevention of the sale of fireworks and enforced use of safety belts in vehicles.

Primary health care programmes should include eye examination at birth, eye screening of pre-school and school children, early management of congenital cataract, vaccination for infectious diseases in children and cooperation between paediatricians and ophthalmologists.

\section{References}

1. Resnikoff $\mathrm{S}$ et al. Global data on visual impairment in the year 2002. Bulletin of the World Health Organization, 2004, 82:844-51.

2. Thylefors B et al. Global data on blindness. Bulletin of the World Health Organization, 1995, 73:115-21.

3. Family health survey 2003. Sana'a, Yemen, Ministry of Health, 2004.

4. Statistical yearbook 2000. Sana'a, Yemen, Central Statistical Organization, Ministry of Planning and Development, 2001.

5. Human development report, 2000/2001. Sana'a, Yemen, Ministry of Planning and Development, 2001 (http://www. ahaunityemen.org/2006new/publications/en/ministry/Human_Development_Report_2000_2001.pdf, accessed 4 October 2009).

6. Al-Mohammadi K. Prevalence of low vision and blindness in age group 50 years and above in Hethran subdistrict, Taiz, Yemen [MSc thesis]. Peshawar, Pakistan, Pakistan Institute of Community Ophthalmology, 2002.

7. Gorafi I. Blindness prevention work in Yemen. Paper presented at the American Academy of Ophthalmology Annual Meeting, New Orleans, Louisiana, 8-11 November, 1998.
8. International statistical classification of diseases and related health problems: tenth revision (ICD 10), vol. 1. Geneva, World Health Organization, 1992.

9. Yorston D. The global initiative Vision 2020: the right to sight. Childhood blindness. Community eye health, 1999, 12(31):44-5.

10. Resnikoff $S$ et al. Global data on visual impairment in the year 2002. Bulletin of the World Health Organization, 2004, 82(11):811-90.

11. Al-Akily S, Bamashmus M. Causes of blindness among adult Yemenis: a hospital-based study. Middle East Africa journal of ophthalmology, 2008, 15:3-6.

12. Bamashmus M, Al-Shabooti A. Is surgical management of cataract and glaucoma patients in Yemen changing? Saudi medical journal, 2004, 25(4):535-6.

13. Bamashmus M, Al-Shabooti A. Childhood eye injuries in Sana'a, Yemen. Middle East journal of ophthalmology, 2002, 10(2):80-1

14. Al-Akily S, Bamashmus M, Khalifa O. Graft survival and visual outcome of 70 corneal grafts in Yemeni patients. Saudi journal of ophthalmology, 2005, 19(1):3-7. 